УДК $628.394(597-25)$

\title{
ИЗУЧЕНИЕ ВИДОВОГО СОСТАВА МИКРООРГАНИЗМОВ, ОСУЩЕСТВЛЯЮЩИХ ОЧИСТКУ СТОЧНЫХ ВОД
}

\author{
Джумагулова Назира Тентимишовна ${ }^{12}$,
} dnazira@rambler.ru

\author{
Гаврилов Иван Евгеньевич², \\ gavrilov.i.e@yandex.ru \\ Нгуен Динь Дап', \\ nguyendinhdap@gmail.com \\ 1 Московский государственный строительный университет, \\ Россия, 129337, г. Москва, Ярославское шоссе, 26 \\ 2 Аграрный университет МСХА им. К.А. Тимирязева, \\ Россия, 127550, г. Москва, ул. Тимирязевская, 49.
}

\begin{abstract}
Актуальность. Одним из наиболее эффективных способов очистки сточных вод является биохимический метод, дающий возможность практически полностью удалить из сточных вод различные растворенные органические вещества. Для улучшения окислительной мощности аэротенков и управления биохимическим процессом очистки сточных вод необходимо было выяснить экспериментально изменчивость биоценоза под влиянием среды и других факторов.

Целью настоящей работы является интенсификация биологической очистки сточных вод за счет непосредственного воздействия на метаболизм микроорганизмов активного ила.

Объекты: видовой и количественный состав микроорганизмов в результате очистки бытовых сточных вод на аэротенках; структуры и состава ферментов, сформировавшихся в процессе очистки.

Методы: исследование биоценоза, методы гидробиологического контроля активного ила и микроскопии активного ила. По исследованиям индикаторных организмов определяется эффективность процесса очистки сточных вод. При микроскопировании активного ила определяют функциональное состояние организмов, особенно индикаторных, подсчитывают организмы тем или иным методом количественного учета, классифицируют их по индикаторным группам, затем определяют тип биоценоза, его характерные особенности. Для исследования микроорганизмов активного ила с помощью микроскопирования используется метод “живой» капли под покровным стеклом.

Результаты. На основе проведенных исследований было выявлено, что снятие загрязнений по аммонийному азоту и фосфору до нормативно-допустимых значений в аэротенках без создания анаэробных зон недостижимо. Присутствие в водной среде органических веществ угнетает развитие нитрифицирующих бактерий, поэтому процесс нитрификации начинается лишь после окисления углеродсодержащих органических соединений, когда создаются условия для первой стадии нитрификации. Нитрифицирующие бактерии также способны накапливать полифосфаты в своих клетках. В обычных условиях биологической очистки, если нитрификация неглубокая, за счет потребления фосфатов бактериями удаляется от 10 до 30 \% растворенных соединений фосфора. Для развития нитрифицирующих бактерий в аэротенках старой конструкции возможно применение прикрепленной микрофлоры с помощью различных загрузок, а также создание в одном из коридоров анаэробных зон, с устройством перемешивающего оборудования и рециркуляции иловой смеси в голову сооружения. Исследование биоценозов активного ила по стадиям его развития позволяет определить доминирующие формы организмов в илах аэротенков, работающих с разными нагрузками на активный ил. При налаженной работе аэротенков в активном иле устанавливается постоянный биоценоз, соответствующий определенной стадии развития ила. Изменение этого биоценоза свидетельствует об изменении режима работы аэротенка.
\end{abstract}

\section{Ключевые слова:}

Активный ил, расход сточных вод, аэротенки, интенсификация процессов очистки, микроорганизмы, биоценоз.

\section{Введение}

До сих пор не существует совершенной системы биоиндикации процесса биологической очистки сточных вод. В процессе очистки происходит последовательность изменения видового состава активного ила, что связано с последовательностью удаления соответствующих субстратов из сточной жидкости. Переход биоценоза из одной стадии развития в другую связан с изменением количества питательных веществ в среде, т. е. в случае процесса с активным илом с нагрузкой по биологическому потреблению кислорода (БПК) на 1 г беззольного вещества [1]. В зависимости от состава сточных вод биоценоз активного ила может харак- теризоваться высоким разнообразием - до 45 видов простейших, с различным численным преобладанием отдельных видов.

В настоящее время аэротенки, применяемые для очистки хозяйственно-бытовых и промышленных вод, с конструктивной точки зрения почти исчерпали свои возможности, позволяющие интенсифицировать процесс биологической очистки [2].

Все существующие отечественные и зарубежные математические моделирования процессов биологической очистки сточных вод разработаны на технологических параметрах работы сооружений (управление содержанием растворенного кислорода или нагрузкой на активный ил). 
В результате решения этих моделей дана рекомендация: строительство сложных многофункциональных очистных сооружений, включающих в свой состав технологическое оборудование различного назначения и принципа действия [3, 4].

Самым перспективным, и в то же время почти неисчерпаемым, можно считать путь интенсификации биологической очистки сточных вод за счет непосредственного воздействия на метаболизм микроорганизмов активного ила $[5,6]$. Знание процессов, которые происходят в активном иле, позволяет оперативно выявлять воздействующие факторы, делать прогноз в процессе очистки сточных вод и, следовательно, управлять этим процес$\operatorname{com}[7,8]$.

Во многих городах и поселках России очистные сооружения городской канализации построены в 60-70 гг. прошлого века [9]. Они исчерпали свои ресурсы, физически устарели и требуют реконструкции. К сбросу очищенных сточных вод предъявляются более жесткие требования по природоохранному нормированию.

Авторами проводились исследования биопленки на биофильтрах с различными загрузочными материалами, для удаления соединений азота из сточных вод в лабораторных условиях [10].

Получены результаты по аммонийному азоту и другим показателям, необходимые для сброса в водоемы рыбохозяйственного назначения, но биофильтры в основном предназначены для малых очистных сооружений [11]. Все организмы, которые входят в биоценоз активного ила, входят в биоценоз живой пленки биофильтров. Однако соотношение организмов в биофильтрах совсем другое, чем в активном иле $[11,12]$.

В процессе очистки производственных сточных вод в последнее время находят широкое применение реагентные и мембранные технологии. Данные технологии ведут к удорожанию процесса очистки сточных вод, кроме того, образуются химические отходы, размещение которых оказывает негативное воздействие на окружающую природную среду. В очистке сточных вод применяются химические, физико-химические, механические и биологические методы. Однако предпочтение следует отдавать биологическому методу очистки сточных вод, как наиболее распространенному и экономически выгодному. В текстильном производстве одним из основных загрязнителей является синтетические поверхностно-активные вещества (СПАВ). СПАВ входят в состав моющих средств и постоянно присутствуют в бытовых сточных водах, а также в производственных сточных водах ряда предприятий [11-14].

Результаты экспериментов показывают, что для снижения концентрации СПАВ до требуемых показателей биохимические методы очистки на аэротенках достаточно эффективны.

Управлять биохимическим процессом очистки сточных вод и значительно интенсифицировать его возможно лишь при условии знания роли опреде- ляющих его факторов: состава микроорганизмов и их биохимических свойств на разных стадиях очистки; взаимоотношений отдельных групп микробов между собой; влияния условий среды (состава и концентрации сточных вод; температуры, $\mathrm{pH}$ ); изменчивости среды и других факторов $[15,16]$.

\section{Материалы и методы}

Для повышения эффективности работы аэрационных сооружений и управления процессами биохимической очистки необходимо провести:

1) анализ качественных и количественных показателей очистки бытовых сточных вод на аэротенках и учет состава биоценоза;

2) исследование структуры и состава ферментов, сформировавшихся в процессе очистки;

3) исследование методов интенсификации работы аэротенков в процессе биологических методов очистки сточных вод.

Для исследования были выбраны аэротенкивытеснители для полной биологической очистки. Расход сточных вод составляет на аэротенке среднем 50 тыс. $\mathrm{m}^{3} /$ сут, средняя доза иловой смеси активного ила $1,5 \mathrm{мг} / л$, содержание растворенного кислорода 2,7 мг/л, иловой индекс 87.

Температура $21,7^{\circ} \mathrm{C}$. В течение 21 дня ежедневно отбирались пробы в осветленной воде после механической очистки, перед поступлением сточной воды в аэротенк. Время пребывания осветленной воды в аэротенке составляет 6-7 часов, поэтому отбор проб очищенной воды производился во второй половине дня.

В очищенной воде исследовались показатели очистки воды, а в иловой смеси - структура и видовой состав активного ила.

Для оценки качества очистки в осветленной и очищенной воде отбирались пробы последующим показателям: взвешенные вещества, нефтепродукты, ПАВ, фосфаты и азот аммонийных солей [16].

Подсчет организмов производится с помощью микроскопирования. После подсчета всей микрофауны рассчитываются: количество видов, отношение прикрепленных микроорганизмов к свободно плавающим (коэффициент К), процентное отношение чувствительных микроорганизмов к устойчивым, индекс Cuba (в нем заложена информация как о количестве видов, так и об их численном распределении по видам) и количество микроорганизмов на дозу ила [17-21].

Отношение прикрепленных микроорганизмов к свободно плавающим [1]:

$$
K=\frac{A}{B},
$$

где $K$ - коэффициент; $A$ - прикрепленные микроорганизмы; $B$ - свободно плавающие микроорганизмы.

Количество микроорганизмов на дозу ила [1]:

$$
C=\frac{X}{V_{\text {кап }} m},
$$


где $C$ - количество организмов в пробе; $X$ - количество экземпляров; $V_{\text {кап }}$ объем капли $(0,01 \mathrm{мл}) ; m-$ доза ила по массе.

Индекс Cuba [1]:

$$
D=N+V \text {, }
$$

где $D$ - индекс Cuba; $N$ - количество видов; $V$ - единица равномерного распределения.

\section{Результаты исследования и обсуждение}

Гидробиологический анализ проб активного ила, отобранных из аэротенка, показал богатый видовой состав приблизительно 37 видов. Для аэротенков, работающих на полную очистку, характерно развитие зооглейных скоплений бактерий и мезасапробных простейших.

Биоценоз активного ила - это гибкий природный механизм, позволяющий сложноорганизованной сточной среде с присущей ей структурной неоднородностью обеспечивать наиболее эффективное распределение субстанций через изменение структуры микроорганизмов. Каждый раз при изменении параметров нагрузки система вынуждена подбирать наиболее эффективную конфигурацию взаимодействия с внешней средой за счет процессов самоорганизации, оптимизирующих это взаимодействие [22-25].

В табл. 1 показан видовой состав активного ила на 26.06.2017 г., отражены количественные параметры.

Для оценки состояния биоценоза активного ила сначала проводился качественный учет разнообразия организмов. Затем в тщательно перемешанной пробе просчитывали их количество. Подсчет организмов ведется с помощью микроскопирования. Сумма каждого отдельного вида микроорганизма в 1 капле (0,01 мл) заноситься в таблицу.

Таблица 1. Количественный и качественный состав биоценоза активного ила

Table 1. Quantitative and qualitative composition of activated sludge biocenosis

\begin{tabular}{|l|c|l|c|}
\hline \multicolumn{1}{|c|}{$\begin{array}{c}\text { Название } \\
\text { Name }\end{array}$} & $\begin{array}{c}\text { Количество } \\
\text { Quantity }\end{array}$ & \multicolumn{1}{|c|}{$\begin{array}{c}\text { Название } \\
\text { Name }\end{array}$} & $\begin{array}{c}\text { Количеств0 } \\
\text { Quantity }\end{array}$ \\
\hline Aspidiscacostata & 714 & Centropixisaculeat & 0 \\
\hline Chilodoncuculus & 214 & Centropixissp & 286 \\
\hline Amphileptusclap & 0 & Pamphagushyalin & 71 \\
\hline Litonotuscarinatus & 0 & Eugliphaacanthop & 143 \\
\hline Spirostomumambigu & 71 & Bodoglobosus & 357 \\
\hline Colepshirtus & 214 & Flagellatasp & 571 \\
\hline Chaetonotusmax & 143 & Mastigamaeba & 71 \\
\hline Epistvlisrotens & 1500 & Amaebaproteus & 143 \\
\hline Epistylisplicatilis & 429 & Amaebamedium & 143 \\
\hline Opercullariacooarc & 0 & Colurellasp & 214 \\
\hline Vorticellaalba & 71 & Rotariarotatoria & 357 \\
\hline Vorticellacovallaria & 357 & Philodinasp & 71 \\
\hline Vorticellanutens & 143 & Lecaneinermis & 143 \\
\hline Zoothamniumsp & 286 & Aeolosomahemprichi & 429 \\
\hline Thuricolasimiles & 214 & Zoogloeauva & 571 \\
\hline Podophriafixa & 0 & Actinomycetes & 0 \\
\hline Tokophryamollis & 0 & Filamentousbacteria & 71 \\
\hline Arcellavulgaris & 857 & & \\
\hline
\end{tabular}

Большое разнообразие видов микроорганизмов, но в то же время неравномерное их количество зависит от расхода сточных вод, их состава и концентрации, температуры, рН. В ходе экспериментов установлено, что если поддерживать основные параметры сооружений - расход сточной воды и нагрузку по БПК стабильными, то сформируется определенный состав биоценоза активного ила.

В состав активного ила входят различные виды бактерий, инфузорий, коловратки, черви и т. д. В нашем случае преобладали следующие виды микроорганизмов:

- простейшие (Amaeba) - голые амебы. Низшие формы их лишены скелета и представляют собой голый комочек цитоплазмы;

- инфузории (Vorticellacovallaria) - одиночные инфузории. Относятся к классу наиболее высокоорганизованных представителей простейших, органами движения которых являются реснички, короткие волосовидные выросты плазмы $[16,19]$;

- коловратки (Rotariarotatoria) - микроскопические многоклеточные животные. У большинства коловраток довольно четко можно выделить головной отдел, туловище и ногу [11-14];

- грибы - составляют обширную группу организмов с совершенно особой биологической организацией. Тело гриба состоит из тонких нитей - гифов, образующих разветвленную структуру, называемую мицелием. Гифы представляют собой жесткие трубочки, заполненные моногоядерной цитоплазмой [15];

- бактерии - нитчатые бактерии, представляющие собой длинные нити из соединительных вместе палочковидных клеток, покрытых общим чехлом. В пределах нити клетки размножаются простым делением. Бактерии играют основную роль в процессах изъятия и окисления органических и некоторых неорганических соединений при очистке сточных вод и самоочищении природных водоемов [26, 27].

Динамика развития микроорганизмов в зависимости от факторов среды представлена на рис. 1.

Из графиков видно, как в течение 21 дня проведения эксперимента сформировался определенный видовой состав биоценоза активного ила.

На рис. 2 представлен суточный расход сточных вод, доза ила и содержание растворенного кислорода во время эксперимента.

Следует отметить, что количественный состав микроорганизмов имеет прямую связь с поступающим расходом сточных вод.

После подсчета всей микрофауны рассчитываются: количество видов, отношение прикрепленных микроорганизмов к свободно плавающим (коэффициент К), процентное отношение чувствительных микроорганизмов к устойчивым, индекс Cuba (в нем заложена информация, как о количестве видов, так и об их численном распределении по видам) и количество микроорганизмов на дозу ила (табл. 2). 

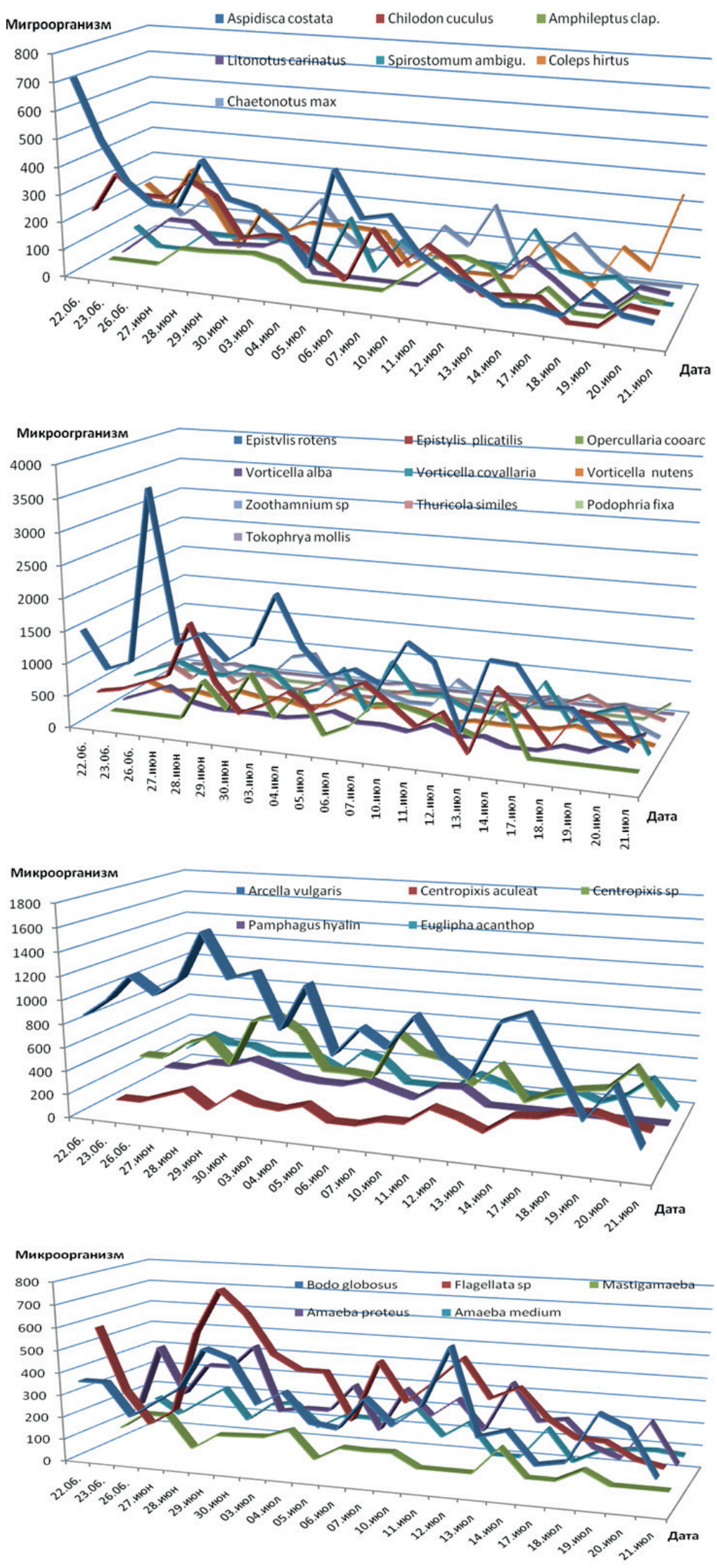

Pис.1. Изменение состава микроорганизмов

Fig. 1. Change of structure of microorganisms 


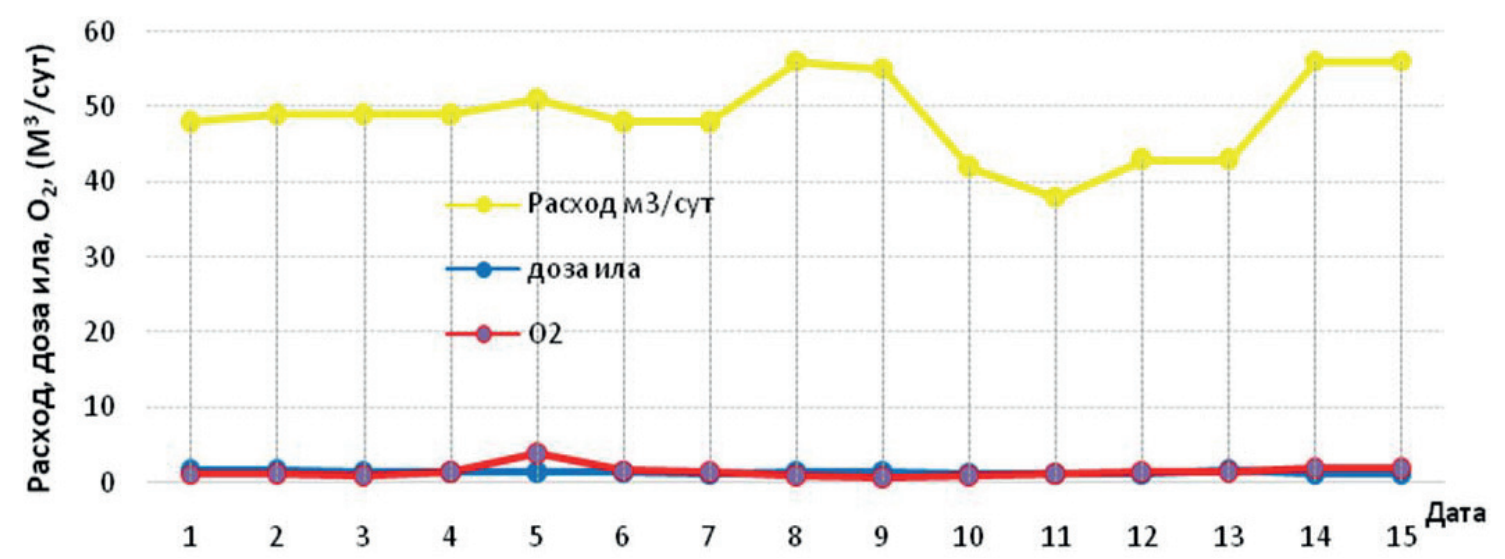

Рис. 2. Характеристики осветленной воды по расходу, дозе ила и растворенному кислороду

Fig. 2. Clarified water characteristics on discharge, sludge dose and dissolved oxygen

Таблица 2. Количественный учет микроорганизмов в активном иле

Table 2. Quantitative assessment of microorganisms in activated sludge

\begin{tabular}{|c|c|c|c|c|c|c|}
\hline \multirow{2}{*}{$\begin{array}{c}\text { Количе- } \\
\text { ство видов } \\
\text { Number } \\
\text { of species }\end{array}$} & \multirow{2}{*}{$\begin{array}{c}\text { Отноше- } \\
\text { ние K } \\
\text { Ratio K }\end{array}$} & \multirow{2}{*}{$\begin{array}{c}\text { Процентное } \\
\text { отношение } \\
\text { Percentage }\end{array}$} & \multicolumn{2}{|c|}{$\begin{array}{c}\text { Коэффициент } \\
\text { Coefficient }\end{array}$} & \multirow{2}{*}{\begin{tabular}{|c|} 
Доза \\
ила \\
Sludge \\
portion
\end{tabular}} & \multirow{2}{*}{\begin{tabular}{|c|} 
Индекс \\
Cuba \\
Cuba \\
Index
\end{tabular}} \\
\hline & & & 1 & 2 & & \\
\hline 8929 & 3000 & 3214 & 0,04 & 0,96 & 1,4 & 28,7 \\
\hline 8714 & 2571 & 3500 & 0,04 & 0,96 & 1,4 & 26,64 \\
\hline 9786 & 3786 & 3643 & 0,03 & 0,97 & 1,4 & 31,78 \\
\hline 12000 & 5429 & 3714 & 0,03 & 0,97 & 1,4 & 29,73 \\
\hline 11214 & 5000 & 3786 & 0,03 & 0,97 & 1,4 & 32,81 \\
\hline 13308 & 3769 & 5385 & 0,03 & 0,97 & 1,3 & 30,76 \\
\hline 12083 & 3917 & 4333 & 0,03 & 0,97 & 1,2 & 32,81 \\
\hline 10000 & 3500 & 3813 & 0,03 & 0,97 & 1,6 & 32,81 \\
\hline 9875 & 4438 & 3188 & 0,04 & 0,96 & 1,6 & 27,67 \\
\hline 9313 & 3750 & 3438 & 0,04 & 0,96 & 1,6 & 27,67 \\
\hline 7000 & 3000 & 2059 & 0,04 & 0,96 & 1,7 & 28,70 \\
\hline 10500 & 4500 & 3500 & 0,04 & 0,96 & 1,6 & 27,67 \\
\hline 8600 & 3533 & 2667 & 0,04 & 0,96 & 1,5 & 28,70 \\
\hline 10714 & 4143 & 3571 & 0,04 & 0,96 & 1,4 & 28,70 \\
\hline 9769 & 3462 & 3000 & 0,04 & 0,96 & 1,3 & 28,70 \\
\hline 6688 & 1750 & 2563 & 0,04 & 0,96 & 1,6 & 27,67 \\
\hline 11143 & 4571 & 3071 & 0,03 & 0,97 & 1,4 & 29,73 \\
\hline 10692 & 4154 & 2923 & 0,03 & 0,97 & 1,3 & 29,73 \\
\hline 7765 & 2588 & 2471 & 0,04 & 0,96 & 1,7 & 28,70 \\
\hline 8615 & 3154 & 2308 & 0,04 & 0,96 & 1,3 & 30,76 \\
\hline 9250 & 2917 & 3083 & 0,03 & 0,97 & 1,2 & 28,70 \\
\hline 5786 & 1929 & 1786 & 0,04 & 0,96 & 1,4 & \begin{tabular}{|l|}
25,60 \\
\end{tabular} \\
\hline
\end{tabular}

Из табл. 2 следует, что биоценоз активного ила имеет хороший видовой состав и все показатели в норме.

На рис. 3 , в табл. 3,4 представлены әффект очистки на выходе из аэротенка следующих веществ: взвешенные вещества, СПАВ и НП.

Как видно из рис. 4 , качество очистки соответствует требованиям предельно допустимого сброca, за исключением тех дней, когда в осветленной воде сильно падает или сильно превышает концентрация взвешенного вещества. В таких случаях возможно биоценоз активного ила испытывает недостаток либо избыток питательных веществ, что приводит к ухудшению качественных показателей. таблица 3. Качество осаждения взвешенных веществ

Table 3. Quality of suspended substance sedimentation

\begin{tabular}{|c|c|c|c|c|}
\hline \multirow[t]{2}{*}{$\begin{array}{l}\text { Дата } \\
\text { Date } \\
(2017)\end{array}$} & \begin{tabular}{|c|} 
Взвешенные \\
вещества \\
(освет. вода) \\
Suspended solids \\
(clarified water)
\end{tabular} & $\begin{array}{c}\text { Взвешенные } \\
\text { вещества } \\
\text { (очищ. вода) } \\
\text { Suspended matter } \\
\text { (cleaned up water) }\end{array}$ & $\begin{array}{c}\text { НДС } \\
\text { Norm } \\
\text { allowable } \\
\text { discharge }\end{array}$ & \multirow[t]{2}{*}{$\begin{array}{c}\text { Расход, } \\
\mathrm{M}^{3} / \text { сут } \\
\text { Water } \\
\text { discharge } \\
\mathrm{m}^{3} / \mathrm{l}\end{array}$} \\
\hline & \multicolumn{3}{|c|}{ мг/л (mg/l) } & \\
\hline 21.06 & 121 & 6,6 & 10 & 55 \\
\hline 22.06 & 105 & 9,6 & 10 & 52 \\
\hline 23.06 & 117 & 8,2 & 10 & 52 \\
\hline 27.06 & 92 & 6,8 & 10 & 38 \\
\hline 28.06 & 60 & 22 & 10 & 52 \\
\hline 29.06 & 178 & 8,6 & 10 & 52 \\
\hline 30.06 & 120 & 4,6 & 10 & 45 \\
\hline 03.07 & 97 & 9 & 10 & 43 \\
\hline 04.07 & 198 & 8,4 & 10 & 68 \\
\hline 05.07 & 209 & 11,2 & 10 & 76 \\
\hline 06.07 & 136 & 10 & 10 & 51 \\
\hline 07.07 & 286 & 15,2 & 10 & 89 \\
\hline 10.07 & 154 & 9 & 10 & 61 \\
\hline 11.07 & 74 & 11,2 & 10 & 53 \\
\hline 12.07 & 119 & 8,6 & 10 & 48 \\
\hline 13.07 & 186 & 5,4 & 10 & 49 \\
\hline 14.07 & 161 & 6,4 & 10 & 49 \\
\hline 17.07 & 96 & 6,8 & 10 & 49 \\
\hline 18.07 & 163 & 5,6 & 10 & 51 \\
\hline 19.07 & 54 & 15,4 & 10 & 48 \\
\hline 20.07 & 76 & 14,2 & 10 & 48 \\
\hline
\end{tabular}

Качество очистки синтетических поверхностно-активных веществ при данном составе биоценоза активного ила значительно ниже нормативно допустимого сброса. В разделе обзора литературы отмечалась возможность применения биохимического метода для очистки сточных вод текстильного производства (непосредственно с варочных цехов).

Для достижения таких же показателей для очистки нефтепродуктов необходимо увеличить дозу активного ила и концентрацию растворенного кислорода на $15-20 \%$. Из табл. 4 следует, что качественные показатели в очищенной воде по нефтепродуктам незначительно превышают нормативно-допустимые сбросы. 


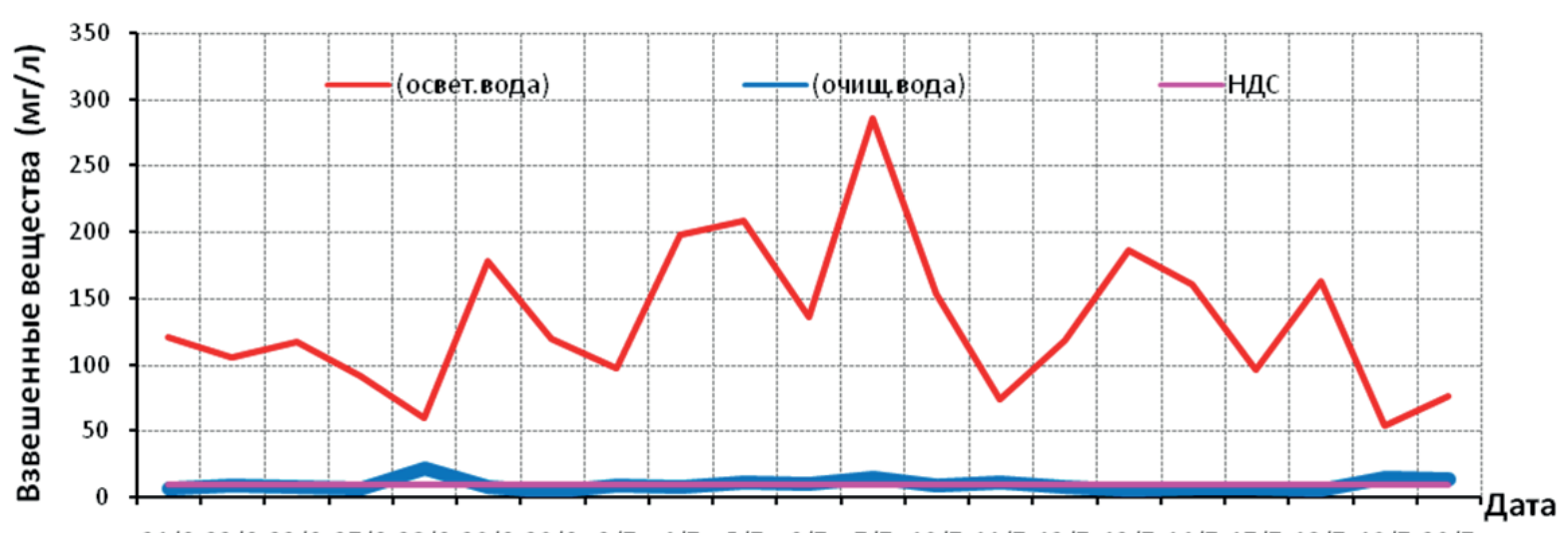

$\begin{array}{lllllllllllllllllllllll}21 / 6 & 22 / 6 & 23 / 6 & 27 / 6 & 28 / 6 & 29 / 6 & 30 / 6 & 3 / 7 & 4 / 7 & 5 / 7 & 6 / 7 & 7 / 7 & 10 / 7 & 11 / 7 & 12 / 7 & 13 / 7 & 14 / 7 & 17 / 7 & 18 / 7 & 19 / 7 & 20 / 7\end{array}$

Рис. 3. Проиесс осаждения взвешенных веществ

Fig. 3. Suspended substance sedimentation

Таблица 4. Качества очистки СПАВ и нефтепродуктов

Table 4. Synthetic surfactants and oil products treatment quality

\begin{tabular}{|c|c|c|c|c|c|c|}
\hline \multirow{3}{*}{$\begin{array}{c}\text { Дата/время } \\
\text { (2017 г.) } \\
\text { Date/time } \\
(2017)\end{array}$} & \multicolumn{3}{|c|}{$\begin{array}{c}\text { Качество очистки СПАВ } \\
\text { Quality of cleaning } \\
\text { synthetic surfactants }\end{array}$} & \multicolumn{3}{|c|}{$\begin{array}{c}\text { Качество очистки } \\
\text { нефтепродуктов } \\
\text { Mineral oil refining quality }\end{array}$} \\
\hline & 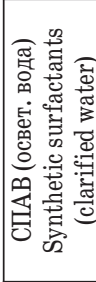 & 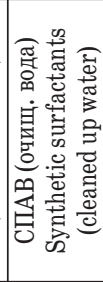 & 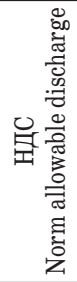 & 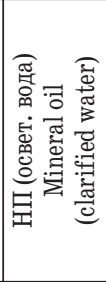 & 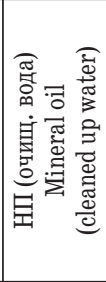 & 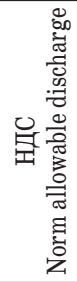 \\
\hline & \multicolumn{6}{|c|}{ мг/л (mg/l) } \\
\hline 21.06 & 2,8 & 0,06 & 0,5 & 2,4 & 0,07 & 0,05 \\
\hline $22.06 / 10-00$ & 2,4 & 0,046 & 0,5 & 1,7 & 0,07 & 0,05 \\
\hline $23.06 / 10-05$ & 1,9 & 0,055 & 0,5 & 2,2 & 0,06 & 0,05 \\
\hline $26.06 / 10-00$ & 2,5 & 0,067 & 0,5 & 2,4 & 0,09 & 0,05 \\
\hline $27.06 / 10-10$ & 2 & 0,057 & 0,5 & 2,8 & 0,07 & 0,05 \\
\hline $28.06 / 10-20$ & 2,4 & 99 & 0,5 & 2,6 & 0,06 & 0,05 \\
\hline $29.06 / 10-00$ & 2,6 & 0,049 & 0,5 & 2,8 & 0,05 & 0,05 \\
\hline $30.06 / 10-15$ & 2,2 & 0,051 & 0,5 & 1,9 & 0,08 & 0,05 \\
\hline $03.07 / 10-00$ & 2,7 & 0,074 & 0,5 & 2,1 & 0,12 & 0,05 \\
\hline $04.07 / 10-00$ & 1,9 & 45 & 0,5 & 2,4 & 0,09 & 0,05 \\
\hline $05.07 / 10-25$ & 3 & 0,071 & 0,5 & 2,4 & 0,12 & 0,05 \\
\hline $06.07 / 10-40$ & 2,3 & 0,064 & 0,5 & 2,6 & 0,11 & 0,05 \\
\hline $07.07 / 10-20$ & 2,1 & 0,06 & 0,5 & 2,3 & 0,09 & 0,05 \\
\hline \begin{tabular}{|l|}
$10.07 / 10-30$ \\
\end{tabular} & 2 & 0,073 & 0,5 & 2,7 & 0,08 & 0,05 \\
\hline 11.07/10-05 & 2,5 & 0,058 & 0,5 & 2,5 & 0,06 & 0,05 \\
\hline \begin{tabular}{|l|}
$12.07 / 10-15$ \\
\end{tabular} & 2,1 & 0,068 & 0,5 & 2,3 & 0,07 & 0,05 \\
\hline $13.07 / 10-25$ & 1,7 & 0,054 & 0,5 & 3,7 & 0,09 & 0,05 \\
\hline 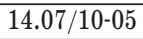 & 2,6 & 0,055 & 0,5 & 2,9 & 0,07 & 0,05 \\
\hline $17.07 / 10-15$ & 3,1 & 0,068 & 0,5 & 3,5 & 0,15 & 0,05 \\
\hline $18.07 / 10-10$ & 2,2 & 0,059 & 0,5 & 3,4 & 0,08 & 0,05 \\
\hline $19.07 / 10-20$ & 2,1 & 0,061 & 0,5 & 2,7 & 0,08 & 0,05 \\
\hline $20.07 / 10-25$ & 2 & 0,063 & 0,5 & 2,3 & 0,09 & 0,05 \\
\hline $21.07 / 10-20$ & 2,6 & 0,049 & 0,5 & 2,5 & 0,07 & 0,05 \\
\hline
\end{tabular}

\section{Выводы и обсуждение}

На основе проведенных исследований было выявлено, что снятие загрязнений по аммонийному азоту и фосфору до нормативно-допустимых значе- ний в аэротенках без создания анаэробных зон недостижимо.

Присутствие в водной среде органических веществ угнетает развитие нитрифицирующих бактерий, поэтому процесс нитрификации начинается лишь после окисления углеродсодержащих органических соединений, когда создаются условия для первой стадии нитрификации. Нитрифицирующие бактерии также способны накапливать полифосфаты в своих клетках. В обычных условиях биологической очистки, если нитрификация неглубокая, за счет потребления фосфатов бактериями удаляется от 10 до $30 \%$ растворенных соединений фоссрора [28].

Для развития нитрифицирующих бактерий в аэротенках старой конструкции возможно применение прикрепленной микрофлоры с помощью различных загрузок, а также создание в одном из коридоров анаэробных зон, с устройством перемешивающего оборудования и рециркуляции иловой смеси в голову сооружения.

Увеличивая или уменьшая приток загрязнений к активному илу, можно искусственно регулировать биоценоз активного ила, скорости его роста и изъятия загрязнений, т. е. количество избыточного ила и качество очищенной сточной жидкости.

Таким образом, исследование биоценозов активного ила по стадиям его развития позволяет определить доминирующие формы организмов в илах аэротенков, работающих с разными нагрузками на активный ил. При налаженной работе аэротенков в активном иле устанавливается постоянный биоценоз, соответствующий определенной стадии развития ила. Изменение этого биоценоза свидетельствует об изменении режима работы аэротенка.

Представляет интерес изучение различной нагрузки на микроорганизмы по загрязняющим веществам, при которой процесс биологической очистки будет протекать в той или иной стадии развития активного ила. 


\section{СПИСОК ЛИТЕРАТУРЫ}

1. Рекомендации по проведению гидробиологического контроля на сооружениях биологической очистки с аэротенками. - М.: Пермь, 2004. - 52 с.

2. Волков С.А., Макиша Е.В. Формирование списков правил для верификации информационных моделей строительных объектов. Ч. 1 // Инженерный вестник Дона. - 2018. - № 4. URL: ivdon.ru/ru/magazine/archive/n4y2018/5347 (дата обращения 01.11.2018).

3. Гогина Е.С., Гульшин И.А. Моделирование энергоэффективного процесса биологической очистки сточных вод в циркуляционном окислительном канале // Водоснабжение и санитарная техника. - 2016. - № 9. - С. 42-48.

4. Гогина Е.С., Гульшин И.А. Удаление азота в модели циркуляционного окислительного канала при пониженном содержании органики в сточных водах // Водоснабжение и санитарная техника. - 2017. - № 12. - С. 26-33.

5. Gulshin I. The settling behavior of an activated sludge with simultaneous nitrification and denitrification // Matec Web of Conferences. - 2017. - № 106. - P. 07002.

6. Алексеев Е.В. Экологические аспекты очистки сточных вод, содержащих биологически стойкие органические вещества // Вода и экология: проблемы и решения. - 2005. - № 4. C. $68-77$.

7. Wang J. Application of radiation technology to sewage sludge processing: a review // Journal of Hazardous Materials. 2007. - V. 143. - Iss. 1-2. - P. 2-7.

8. Factors affecting disinfection and stabilization of sewage sludge / A. Bethany, S. Robert, Jr. Smith, E. James, D. Suresh // Proc. of the Water Environment Federation. - Publisher: Water Environment Federation. - 2006. - Session 61 through session 70. P. 5345-5361.

9. Кузнецов Н.Б. Прикладная экобиотехнология. 3-е изд., доп. M.: БИНОМ, 2015. - 629 c.

10. Gogina E.S., Yantsen O.V. Research of biofilter feed properties // International Journal of Applied Engineering Research. 2015. - T. 10. - № 24. - Р. 44070-44074.

11. Интенсификация процессов удаления соединений азота из сточных вод на биофильтрах / Е.С. Гогина, 0.В. Янцен, 0.А. Ружицкая, В. Дабровски, Р. Жилка, Д. Боружко // Вода и экология. - 2016. - № 3. - С. 35-46.

12. Gogina E., Gulshin I. Simultaneous denitrification and nitrification in the lab-scale oxidation with low $\mathrm{C} / \mathrm{N}$ ratio // Procedia Engineering. - 2015. - V. 117. - P. 107-113.

13. Gogina E., Gulshin I. The single-sludge dinitri-nitrification system in reconstruction of wastewater treatment plants in the Russian Federation // Applied Mechanics and Materials. - 2015. T. 580-583. - P. 2367-2369.

14. Gogina E., Ruzhitskaya 0. One-sludge dinitri-nitrification system in reconstruction of biological treatment stations in Russian Federation Applied Mechanics and Materials. - 2015. V. 726-727. - P. 1325-1331.

15. Алексеев Е.В. Физико-химическая очистка сточных вод. - М.: Изд-во АСВ, 2007. - 248 с.
16. Ruzhitskaya 0., Yantsen 0. Wastewater treatment to remove phosphates and organic pollutions // International Journal of Applied Engineering Research. - 2016. - T. 11. - № 5. P. 3496-3498.

17. Laboratory research of zeolit use for treatment of wastewater of different origin / N. Makisha, Yu. Voronov, E. Poupyrev, V. Volshanik // International Journal of Applied Engineering Research. - 2015. - V. 10. - № 21. - P. 41919-41922.

18. Zaletova N., Voronov Yu., Makisha N. Conditions of advanced removal of phosphorus at wastewater treatment plants // International Journal of Applied Engineering Research. - 2015. V. 10. - № 21. - P. 42544-42555.

19. Gulshin I., Kuzina A. Adaptation of nitrifying activated sludge to simultaneous nitrification and denitrification in the lab-scale oxidation ditch // International Journal of Applied Engineering Research. - 2015. - V. 10. - № 21. - P. 42618-42455.

20. Percolation units for wastewater treatment / N. Makisha, V. Scherbakov, A. Smirnov, E. Sherbina // International Journal of Applied Engineering Research. - 2015. - V. 10. - № 24. -P. 444347-44349.

21. Calculation of biogas facilities of recycling of organic sewage sludge of breeding factories / V. Sherbakov, E. Gogina, T. Schukina, N. Kuznetsova, N. Makisha, E. Poupyrev // International Journal of Applied Engineering Research. - 2015. - V. 10. № 24. - P. 444347-44349.

22. Козлов М.Н., Дорофеев А.Г., Асеева В.Г. Микробиологический контроль активного ила биореакторов очистки сточных вод от биогенных элементов. - М.: Изд-во «Наука», 2012. - 80 с.

23. Жмур Н.С. Технологические и биохимические процессы очистки сточных вод на сооружениях с аэротенками. - М.: AKBAPOC, 2003. - $507 \mathrm{c.}$

24. Евсеева Т.И., Мелехова 0.П., Саранульцева Е.И. Биологический контроль окружающей среды. Биоиндикация и биотестирование. 2-е изд., доп. - М.: Академия, 2008. - 288 с.

25. Методические указания по отбору проб для анализа сточных вод. ПНД Ф 12.15.1-08. -М/: Госсанэпиднадзор, 2008. - 23 с.

26. Будник Л.И., Джумагулова Н.Т. Методы биотестирования в системе экологического мониторинга водной среды // Проблемы устойчивости и безопасности систем жизнеобеспечения в сфере жилищно-коммунального хозяйства: Материалы Международной научно-практической конференции. - М.: Изд-во Леонид Будник, 2011. - С. 279-285.

27. Будник Л.И., Сотникова Л.А., Джумагулова Н.Т. Некоторые аспекты математического обеспечения системы экологического мониторинга водных объектов // Водоснабжение и водоотведение мегаполиса: Материалы II международной научно-практической конференции. - М.: Изд-во Леонид Будник, 2011. C. 312-323.

28. Большаков Н.Ю. Очистка от биогенных элементов на городских очистных сооружениях. - М.: Изд-во СПб Политехнического университета, 2010. - 112 с.

Поступила 12.11.2018 2.

\section{Информация об авторах}

Джумагулова Н.T., кандидат технических наук, доцент кафедры гидравлики и гидротехнического строительства Московского государственного строительного университета; доцент кафедры организации и технологии стрительства объектов Аграрного университета МСXА им. К.А. Тимирязева.

Гаврилов И.Е., ассистент кафедры организации и технологии стрительства объектов Аграрного университета МСХА им. К.А. Тимирязева.

Нгуен Динь Дап, аспирант кафедры гидравлики и гидротехнического строительства Московкого государственного строительного университета. 
UDC $628.394(597-25)$

\title{
STUDYING SPECIES COMPOSITION OF MICROORGANISMS PERFORMING WASTEWATER TREATMENT
}

\author{
Nazira T. Dzhumagulova ${ }^{1,2}$, \\ dnazira@rambler.ru \\ Ivan E. Gavrilov², \\ gavrilov.i.e@yandex.ru \\ Nguyen Dinh Dap', \\ nguyendinhdap@gmail.com \\ 1 Moscow State University of Civil Engineering, \\ 26, Yaroslavskoe road, Moscow, 129337, Russia. \\ ${ }^{2}$ Agrarian University named after K.A. Timiryazev, \\ 49, Timiryazevskaya street, Moscow, 127550, Russia.
}

\begin{abstract}
The relevance. One of the most effective methods of wastewater treatment is the biochemical one, which makes it possible to remove almost completely various dissolved organic substances from wastewater. To improve the oxidative power of aeration tanks and control the biochemical process of wastewater treatment, it was necessary to determine experimentally the variability of the biocenosis under the influence of the environment and other factors.

The main aim of the research is to intensify biological wastewater treatment by means of direct effect upon the metabolism of activated sludge microorganisms

Objects: species and quantitative composition of microorganisms as a result of treatment of domestic wastewater in aeration tanks; structure and composition of enzymes formed at purification.

Methods: research of biocenosis, methods of hydrobiological control of activated sludge and microscopy of activated sludge. During microscopy of activated sludge, the functional state of organisms, especially indicator ones, is determined, organisms are counted by one or another method of quantitative accounting, they are classified by indicator groups, then the type of biocenosis and its characteristic features are determined. To study microorganisms of activated sludge using microscopy, the method of «live» drops under a coverslip is used.

Results. Based on the carried out research it was identified that the removal of ammonium nitrogen and phosphorus pollution to standard allowable value in continuous-flow aerotanks without anaerobic zones is unattainable. Organic matters in aquatic medium oppress nitrifying bacteria development, therefore nitrification begins only after oxidation of carboniferous organic compounds under the conditions of the first stage of nitrification. Nitrobacteria are also capable to accumulate polyphosphates in their cells. Normally, considering superficial nitrification and phosphates demand of bacteria, biological treatment removes from 10 to $30 \%$ of the dissolved phosphorus compounds. For developing nitrobacteria in retrofit designed aerotanks, it is possible to apply the attached microflora by means of various loadings and creation of anaerobic zones in one of the corridors, with the mixer and recycling of sludge mix in the construction head. The research of activated sludge biocenosis on its development stages helps determine the dominating forms of organisms in aerotanks working with different sludge loads. Smooth aerotank operating in activated sludge allows the constant biocenosis corresponding to a particular developmental stage. Biocenosis change demonstrates the change of aerotank operating mode.
\end{abstract}

Key words:

Activated sludge, sewage flow rate, aerotanks, water treatment intensification, microorganisms, biocenosis.

\section{REFEPENCES}

1. Rekomendatsii po provedeniyu gidrobiologicheskogo kontrolya na sooruzheniyakh biologicheskoy ochistki s aerotenkami [Recommendations on conducting hydrobiological control on biological treatment facilities by aerotanks]. Moscow, Perm Publ., 2004. $52 \mathrm{p}$.

2. Volkov S. A., Makisha E. V. Formirovanie spiskov pravil dlya verifikatsii informatsionnykh modeley stroitelnykh obektov. Ch. 1 [Formation of lists of rules for verification of information models of construction objects. P. 1]. Engineering Bulletin of the Don, 2018, no. 4. Available at: ivdon.ru/ru/magazine/archive/n4y2018/5347 (accessed 01 November 2018).

3. Gogina E.S., Gulshin I.A. Modelirovanie energoeffektivnogo protsessa biologicheskoy ochistki stochnykh vod v tsirkulyatsionnom okislitelnom kanale [Modeling energy-efficient biological wastewater treatment in a circulating oxidizing channel]. Vodosnabzhenie $i$ sanitarnaya tekhnika, 2016, no. 9, pp. 42-48.

4. Gogina E.S., Gulshin I.A. Udalenie azota v modeli tsirkulyatsionnogo okislitelnogo kanala pri ponizhennom soderzhanii organiki v stochnykh vodakh [Nitrogen removal in a model of a circulating oxidizing channel with a low organic content in wastewater]. Vodosnabzhenie i sanitarnaya tekhnika, 2017, no. 12, pp. 26-33

5. Gulshin I. The settling behavior of an activated sludge with simultaneous nitrification and denitrification. Matec Web of Conferences, 2017, no. 106, pp. 07002.

6. Alekseev E.V. Ecological aspects of wastewater treatment containing biologically resistant organic substances. Water and ecology: problems and solutions, 2015, no. 4, pp. 68-77. In Rus.

7. Wang J. Application of radiation technology to sewage sludge processing: a review. Journal of Hazardous Materials, 2007, vol. 143, Iss. 1-2, pp. 2-7.

8. Bethany A., Robert S., Smith Jr., James E., Suresh D. Factors affecting disinfection and stabilization of sewage sludge. Proc. of the Water Environment Federation, Publisher: Water Environment Federation, 2006, Session 61 through session 70, pp. 5345-5361.

9. Kuznetsov N.B. Prikladnaya ekobiotekhnologiya [Applied ecobiotechnology. $3^{\text {rd }}$ ed]. Moscow, BINOM. Laboratory of Knowledge Publ., 2015. 629 p. 
10. Gogina E.S., Yantsen 0.V. Research of biofilter feed properties. International Journal of Applied Engineering Research, 2015, vol. 10, no. 24, pp. 44070-44074.

11. Gogina E.S., Yantsen O.V., Ruzhitskaya O.A., Dabrowski V., Zhilka R., Boruzhko D. Intensification of processes of removal of nitrogen compounds from wastewater on biofilters. Water and ecology: problems and solutions, 2016, no. 3, pp. 35-46. In Rus.

12. Gogina E., Gulshin I. Simultaneuos denitrification and nitrification in the lab-scale oxidation ditcn with low $\mathrm{C} / \mathrm{N}$ ratio. Procedia Engineering, 2015, vol. 117, pp. 107-113.

13. Gogina E., Gulshin I. The single-sludge denitri-nitrification system in reconstruction of wastewater treatment plants in the Russian Federation. Applied Mechanics and Material, 2015, vol. 580-583, pp. 2367-2369.

14. Gogina E., Ruzhitskaya 0. One-sludge dinitri-nitrification system in reconstruction of biological treatment stations in Russian Federation. Applied Mechanics and Materials, 2015, vol. 726-727, pp. $1325-1331$.

15. Alexeev E.V. Fiziko-khimicheskaya ochistka stochnykh vod [Physicochemical treatment of wastewater]. Moscow, ACU Publ. house of the, 2007. pp. 196-205.

16. Ruzhitskaya 0., Yantsen 0. Wastewater treatment to remove phosphates and organic pollutions. International Journal of $A p$ plied Engineering Research, 2016, vol. 11, no. 5, pp. 3496-3498.

17. Makisha N., Voronov Yu., Poupyrev E., Volshanik V. Laboratory research of zeolit use for treatment of wastewater of different origin. International Journal of Applied Engineering Research, 2015, vol. 10, no. 21, pp. 41919-41922.

18. Zaletova N., Voronov Yu., Makisha N. Conditions of advanced removal of phosphorus at wastewater treatment plants. International Journal of Applied Engineering Research, 2015, vol. 10, no. 21, pp. 42544-42555.

19. Gulshin I., Kuzina A. Adaptation of nitrifying activated sludge to simultaneous nitrification and denification in the lab-scale oxidation ditch. International Journal of Applied Engineering Research, 2015, vol. 10, no. 21, pp. 42618-42455.

20. Makisha N., Scherbakov V., Smirnov A., Sherbina E. Percolation units for wastewater treatment. International Journal of Applied Engineering Research, 2015, vol. 10, no. 24, pp. 444347-44349.

21. Sherbakov V., Gogina E., Schukina T., Kuznetsova N., Makisha N., Poupyrev E. Calculation of biogas facilities of recycling of organic sewage sludge of breeding factories. International Journal of Applied Engineering Research, 2015, vol. 10, no. 24, pp. 444347-44349.
22. Kozlov M.N., Dorofeev A.G., Aseeva V.G. Mikrobiologicheskiy kontrol aktivnogo ila bioreaktorov ochistki stochnykh vod ot biogennykh elementov [Microbiological control of active sludge of bioreactors of wastewater treatment from biogenic elements]. Moscow, Nauka Publ., 2012. 80 p.

23. Zhmur N.S. Tekhnologicheskie i biokhimicheskie protsessy ochistki stochnykh vod na sooruzheniyakh s aerotenkami [Technological and biochemical processes of wastewater treatment at structures with aerotanks]. Moscow, AKVAROS Publ., 2003. pp. 312-317.

24. Evseeva T.I., Melekhova 0.P., Saranultseva E.I. Biologicheskiy kontrol okruzhayushchey sredy. Bioindikatsiya i biotestirovanie [Biological control of the environment. Bioindication and biotesting]. Moscow, Akademiya Publ., 2008. pp. 211-214.

25. Metodicheskie ukazaniya po otboru prob dlya analiza stochnykh vod. PND F 12.15.1-08 [Methodological instructions for sampling for the analysis of sewage PND F 12.15.1-08]. Mosocw, Gossanepidnadzor Publ., 2008. pp. 5-12.

26. Budnik L.I., Dzhumagulova N.T. Metody biotestirovaniya v sisteme ekologicheskogo monitoringa vodnoy sredy [Methods of biotesting in the system of ecological monitoring of the aquatic environment]. Problemy ustoychivosti i bezopasnosti sistem zhizneobespecheniya $v$ sfere zhilishchno-kommunalnogo khozyaystva. $M a$ terialy Mezhdunarodnoy nauchno-prakticheskoy konferentsii [Materials of the International Scientific and Practical Conference. Problems of sustainability and safety of life support systems in the sphere of housing and communal services]. Moscow, Leonid Budnik Publ., 2011. pp. 279-285.

27. Budnik L.I, Sotnikova L.A., Dzhumagulova N.T. Nekotorye aspekty matematicheskogo obespecheniya sistemy ekologicheskogo monitoringa vodnykh obektov [Some aspects of the mathematical support of the system of ecological monitoring of water bodies]. Vodosnabzhenie i vodootvedenie megapolisa. Materialy II mezhdunarodnoy nauchno-prakticheskoy konferentsii [Materials of the second international scientific and practical conference. Water supply and water management of a megacity]. Mosocw, Leonid Budnik Publ., 2011. pp. 312-323.

28. Bolshakov N.Yu. Ochistka ot biogennykh elementov na gorodskikh ochistnykh sooruzheniyakh [Cleaning from biogenic elements in urban wastewater treatment plants]. Moscow, St. Peteburg Polytechnic University Publ., 2010. pp. 109-112.

Received: 12 November 2018.

\section{Information about the authors}

Nazira T. Dzhumagulova, Cand. Sc., associate professor, Moscow State University of Civil Engineering; associate professor, Agrarian University named after K.A. Timiryazev.

Ivan E. Gavrilov, assistant, Agrarian University named after K.A. Timiryazev.

Nguyen Dinh Dap, postgraduate, Moscow State University of Civil Engineering. 